Published in final edited form as:

J Vasc Interv Radiol. 2017 July ; 28(7): 971-977.e4. doi:10.1016/j.jvir.2017.04.016.

\title{
Adjuvant medications that improve survival after locoregional therapy
}

\author{
F. Edward Boas, MD, PhD, \\ Interventional Radiology Service, Department of Radiology, Memorial Sloan Kettering Cancer \\ Center, 1275 York Ave., New York, NY 10065
}

Etay Ziv, MD, PhD, Interventional Radiology Service, Department of Radiology, Memorial Sloan Kettering Cancer Center, 1275 York Ave., New York, NY 10065

Hooman Yarmohammadi, MD,

Interventional Radiology Service, Department of Radiology, Memorial Sloan Kettering Cancer Center, 1275 York Ave., New York, NY 10065

Karen T. Brown, MD, Interventional Radiology Service, Department of Radiology, Memorial Sloan Kettering Cancer Center, 1275 York Ave., New York, NY 10065

Joseph P. Erinjeri, MD, PhD, Interventional Radiology Service, Department of Radiology, Memorial Sloan Kettering Cancer Center, 1275 York Ave., New York, NY 10065

Constantinos T. Sofocleous, MD, PhD, Interventional Radiology Service, Department of Radiology, Memorial Sloan Kettering Cancer Center, 1275 York Ave., New York, NY 10065

James J. Harding, MD, and Gastrointestinal Medical Oncology Service, Department of Medicine, Memorial Sloan Kettering Cancer Center, 1275 York Ave., New York, NY 10065

Stephen B. Solomon, MD Interventional Radiology Service, Department of Radiology, Memorial Sloan Kettering Cancer Center, 1275 York Ave., New York, NY 10065

\section{Abstract}

Purpose-To determine if outpatient medications taken at the time of liver tumor embolization or ablation affect survival.

Correspondence to: F. Edward Boas.

Presented at SIR 2017

Publisher's Disclaimer: This is a PDF file of an unedited manuscript that has been accepted for publication. As a service to our customers we are providing this early version of the manuscript. The manuscript will undergo copyediting, typesetting, and review of the resulting proof before it is published in its final citable form. Please note that during the production process errors may be discovered which could affect the content, and all legal disclaimers that apply to the journal pertain. 
Methods-An IRB-approved retrospective review was performed of 2032 liver tumor embolization, radioembolization, and ablation procedures on 1092 patients from June 2009 to April 2016. For each patient, the following information was analyzed: pathology, hepatocellular carcinoma (HCC) stage (AJCC), neuroendocrine tumor (NET) grade, initial locoregional therapy, overall survival after initial locoregional therapy, Child Pugh score, ECOG performance status, Charlson comorbidity index, and outpatient medications taken at the time of locoregional therapy. Kaplan Meier survival curves were calculated for patients taking 29 medications or medication classes (including both prescription and non-prescription medications), which the patient was taking for reasons unrelated to their primary cancer diagnosis. Kaplan Meier curves were compared using the log-rank test.

Results-For HCC patients initially treated with embolization ( $n=304$ patients), the following medications were associated with improved survival when taken at the time of embolization: beta blockers $(p=0.0007)$, aspirin $(p=0.0008)$ and other NSAIDs $(p=0.009)$, proton pump inhibitors ( $p=0.004)$, and antivirals for HBV or HCV ( $p=0.01$ ). For colorectal liver metastases initially treated with ablation ( $n=172$ patients), beta blockers were associated with improved survival when taken at the time of ablation $(p=0.02)$. For NET patients initially treated with embolization, and colorectal patients initially treated with radioembolization, there was no association between medications and survival.

Conclusion-Aspirin and beta blockers are associated with significantly improved survival when taken at the time of embolization for HCC. Aspirin was not associated with survival differences after locoregional therapy for NET or colorectal liver metastases, suggesting an HCCspecific effect.

\section{Introduction}

Locoregional therapies for liver tumors - thermal ablation, embolization, and radioembolization - trigger a cascade of downstream effects that can affect local recurrence as well as growth of distant tumors. After thermal ablation, immune cells infiltrate the ablation zone, which can result in either an antitumor immune response, or immune tolerance for tumor antigens (1). Growth factors released after liver ablation can cause progression of tumors outside the ablation zone (2). After transarterial embolization, tumor ischemia stimulates angiogenesis and growth of the residual viable tumor $(3,4)$. Embolization can also induce an anti-tumor immune response: for example, by increasing alpha-fetoprotein (AFP)-specific CD4+ T cells after embolization of hepatocellular carcinoma (HCC) (5), or by decreasing regulatory T cells (6).

These downstream effects can be modulated by oral medications, which can thus affect outcomes after locoregional therapy. A randomized trial showed that oral ginsenoside $\mathrm{Rg} 3$, a ginseng extract with anti-inflammatory and anti-angiogenic effects, improved survival after transarterial chemoembolization (TACE) of HCC (7). Sorafenib, an oral anti-angiogenesis agent, might improve survival after TACE of advanced $\operatorname{HCC}(4,8)$. Bumetanide, a diuretic that also inhibits glycolysis, increased tumor necrosis after transarterial embolization (TAE) of HCC in an animal model (9). Celecoxib, an anti-inflammatory agent (cyclooxygenase-2 inhibitor), reduced distant tumor growth after liver ablation in an animal model (10). 
The goal of this study was to find medications that improve survival after liver-directed locoregional therapy. This study examined outpatient medications (including both prescription and non-prescription medications), which the patient was taking for reasons unrelated to their primary cancer diagnosis. These medications are all FDA-approved and have known safety profiles. Many of these medications have known effects on inflammation, angiogenesis, blood flow, or glucose metabolism, and thus might have a synergistic effect with locoregional therapy (Table 1).

\section{Materials and Methods}

This HIPAA-compliant retrospective study was approved by the IRB. All liver tumor embolization, radioembolization, and ablation procedures performed from June 2009 to April 2016 were reviewed: 2032 procedures on 1092 patients. There were no exclusion criteria.

The most common pathologies were: HCC (30\%), colorectal liver metastases (23\%), and NET (20\%). The initial procedure was transarterial embolization in $60 \%$ of patients, radioembolization in $14 \%$, and ablation in $26 \%$ (Supplemental Table 1). Average age at the time of initial locoregional therapy was 62 , and $58 \%$ of patients were male.

Patients were grouped based on pathology and type of initial locoregional therapy. The most common treatment groups were: embolization of HCC (11) ( $n=304$ patients), embolization of NET (12) ( $n=199$ ), ablation of colorectal liver metastases (13) ( $n=172)$, and radioembolization of colorectal liver metastases (14) $(n=67)$. The association between outpatient medications and survival was analyzed for these 4 treatment groups (Figure 1).

For each patient, the type of initial locoregional therapy (embolization, radioembolization, or ablation), and overall survival after initial locoregional therapy was recorded. The date of death was obtained from the Social Security Death Index, records of in-hospital deaths, or information provided by third parties (such as patient family members) to the hospital billing department or other hospital staff. The type of liver tumor was based on pathology (if available), or an imaging diagnosis (if not available). For HCC, the AJCC stage was recorded, and for neuroendocrine tumor (NET), the grade was determined from a biopsy specimen. Child Pugh score, ECOG performance status, and age-adjusted Charlson comorbidity index just prior to the initial locoregional therapy were recorded. The Charlson comorbidity index provides an estimate of the risk of post-operative mortality due to age and comorbidities (15). The Charlson comorbidity index includes: myocardial infarction, congestive heart failure, peripheral vascular disease, cerebrovascular disease, diabetes, chronic pulmonary disease, renal disease, and several other comorbidities. Finally, outpatient medications taken 7 days before through 30 days after locoregional therapy were recorded. Vitamin and mineral supplements were only counted if specific vitamins or minerals were listed; multivitamins were not counted.

Patients took a total of 543 different medications at the time of locoregional therapy. For each of these medications, a literature search (using PubMed) was performed to determine if any of these medications had a known or suspected effect on cancer, or a known or 
suspected synergistic effect with embolization, radioembolization, or ablation, using the keywords listed in Supplemental Box 1. Based on this literature search, and the therapeutic category of each medication, we selected a subset of 29 medications and medication classes that were non-chemotherapy medications, and were taken by at least 20 patients (Table 1, Figure 2). Many of these medications have a known or suspected effect on cancer, or a known or suspected synergistic effect on locoregional therapy.

For each treatment group, Kaplan Meier survival curves were calculated for patients taking versus not taking these 29 medications or medication classes (Table 1). Kaplan Meier curves (for patients taking versus not taking a medication) were compared using the log-rank test. A Bonferroni correction was applied for multiple comparisons. Child Pugh score and Charlson comorbidity index for patients taking versus not taking a medication were compared using a $t$-test. ECOG performance status, HCC stage, and NET grade were compared using a chisquared test. Statistical tests were performed in Mathematica 9.

\section{Results}

\section{Embolization of HCC}

The following medications were associated with improved survival when taken at the time of embolization of HCC: beta blockers, aspirin and other NSAIDs, proton pump inhibitors, and antivirals for $\mathrm{HBV}$ or $\mathrm{HCV}$ (Table 2). Using a p-value cutoff of 0.0017 (Bonferroni correction for multiple comparisons), both aspirin and beta blockers remain statistically significantly associated with improved survival after embolization for HCC (Figure 2, Figure 3, and Figure 4). For patients who received embolization for HCC: 42 of 304 were taking aspirin, and 35 of 42 were taking aspirin $81 \mathrm{mg}$ daily; 68 of 304 were taking beta blockers, most commonly metoprolol.

Beta blockers and aspirin are typically taken together ( $\mathrm{p}<0.0001$, Fisher's exact test): $71 \%$ of patients on aspirin were also taking a beta blocker, and $44 \%$ of patients on beta blockers were also taking aspirin. There was a survival benefit associated with taking both aspirin and beta blockers, compared to taking neither $(p=0.00036)$. However, there was no survival benefit associated with taking only aspirin versus neither $(p=0.53)$, only beta blockers versus neither $(p=.18)$, both versus only beta blockers $(p=0.063)$, or both versus only aspirin $(p=0.12)$. Thus, it is unclear whether the survival benefit is due to aspirin, beta blockers, or both in combination.

For all medications associated with a survival benefit (beta blockers, aspirin and other NSAIDs, proton pump inhibitors, and antivirals for HBV or HCV), there was no significant difference in HCC stage, Child Pugh score, ECOG performance status, or Charlson comorbidity index for patients taking versus not taking the medication (Supplemental Table 2).

\section{Embolization of NET}

No medications were associated with survival differences after embolization of NET liver metastases (Supplemental Table 3). Thus, medications associated with improved survival 
when taken at the time of embolization for HCC had no effect on survival when taken at the time of embolization for NET.

\section{Ablation of colorectal liver metastases}

Beta blockers were associated with improved survival when taken at the time of ablation of colorectal liver metastases (Table 2). However, this association was no longer statistically significant after correcting for multiple comparisons.

Patients taking beta blockers at the time of ablation of colorectal liver metastases had an average ECOG performance status of 0.17 , compared to 0.01 for patients not taking beta blockers ( $p=0.0002$ ). There was no difference in Child Pugh score or age-adjusted Charlson comorbidity index for patients taking versus not taking beta blockers. Despite having slightly worse performance status, patients taking beta blockers had improved survival.

\section{Radioembolization of colorectal liver metastases}

No medications were associated with survival differences after radioembolization of colorectal liver metastases (Supplemental Table 3). Thus, medications associated with improved survival when taken at the time of embolization for HCC had no effect on survival when taken at the time of radioembolization for colorectal liver metastases.

\section{Discussion}

Aspirin and beta blockers are associated with significantly improved survival when taken at the time of embolization for HCC. Several other medications show some promise as adjuvants to locoregional therapy: proton pump inhibitors for HCC embolization, HBV or $\mathrm{HCV}$ antivirals (but not other antivirals) for HCC embolization, and beta blockers for ablation of colorectal liver metastases.

Aspirin inhibits hypoxia-induced angiogenesis $(16,17)$, which might prevent TAE-induced ischemia from promoting angiogenesis and growth of the residual viable tumor $(3,4)$. Aspirin also inhibits glycolysis (18), which might make tumor cells less likely to survive TAE-induced ischemia (9). Aspirin is a cyclooxygenase (COX) inhibitor, and COX-2 is known to be overexpressed in well differentiated HCC (19). COX-2 inhibition promotes an anti-tumor immune response (20), and also inhibits growth of HCC (21) in animal models.

Chronic inflammation plays a key role in cancer development, and this can be blocked by NSAIDs (22). Randomized trials have shown that aspirin decreases the risk of death from colorectal cancer, pancreatic cancer, and other adenocarcinomas (23). Retrospective studies have shown that aspirin reduces the risk of developing HCC (24), reduces the risk of death from chronic liver disease (24) (possibly by decreasing chronic liver inflammation), reduces the risk of metastasis of adenocarcinoma (25), and improves survival after TACE for HCC (26).

This study showed that aspirin and also other NSAIDs (most commonly, ibuprofen and naproxen) are associated with improved survival after TAE for HCC. Aspirin, ibuprofen, and naproxen are all non-selective COX inhibitors with anti-inflammatory properties. However, 
other immune modulating medications, such as corticosteroids or G-CSF, were not associated with any survival differences after embolization in this study. Aspirin was not associated with any survival differences after locoregional therapy for NET or colorectal cancer. This suggests a specific effect of aspirin on HCC, possibly related to COX inhibition.

Beta blockers decrease blood flow in the portal vein, and decrease the risk of variceal bleeding (27). Decreased portal flow is associated with improved response after radioembolization of colorectal liver metastases (28). Beta blockers also reduce stresshormone-mediated invasion of tumor cells $(29,30)$.

Beta blockers decrease the risk of developing HCC in patients with cirrhosis (31). Beta blockers are also cardioprotective, and reduce mortality after major surgery (32). Other antihypertensive medications were not associated with survival differences in this study, which suggests that beta-blockers do not improve survival after HCC embolization by lowering blood pressure.

Based on the evidence presented above, we believe that aspirin and beta blockers are responsible for improving survival when combined with embolization of HCC. No other clinical variable was different in the medication groups (tumor stage, liver disease, performance status, comorbidities, prior treatment, embolization technique). Published laboratory, animal, and clinical data reviewed above show that both aspirin and beta blockers have an anti-HCC effect. The improved survival is likely due to an HCC-specific mechanism, and not a cardioprotective mechanism, because aspirin and beta blockers were not associated with improved survival when combined with arterially directed therapy for neuroendocrine tumor or colorectal liver metastases.

Limitations of this study include its retrospective design, and insufficient power to examine the effects of less common medications. The results should be validated in a prospective study. In addition, given the number of different medications examined, the magnitude of the survival benefit is likely to be over-estimated in this study. The data on vitamin and mineral supplements only includes patients taking specific supplements, and does not include vitamin and mineral intake from multivitamins or from food. Finally, given the positive correlation between aspirin and beta blocker usage, it is unclear which medication is responsible for the improvement in survival.

In conclusion, aspirin and other NSAIDs were associated with improved survival after embolization of HCC, possibly due to an anti-inflammatory, anti-angiogenic, or antiglycolytic mechanism. Beta blockers were also associated with improved survival after embolization of HCC, possibly due to decreased portal flow, decreased tumor stress response, or cardioprotective effects. Aspirin and beta blockers were not associated with survival differences after embolization of neuroendocrine tumor, or radioembolization of colorectal liver metastases, suggesting an HCC-specific effect. Future experiments should test the actual role of these proposed mechanisms.

\section{Supplementary Material}

Refer to Web version on PubMed Central for supplementary material. 


\section{Acknowledgments}

Daniel Kelly wrote queries to extract information from our hospital's clinical database. This research was funded in part through an NIH/NCI Cancer Center Support Grant (P30 CA008748).

\section{References}

1. Chu KF, Dupuy DE. Thermal ablation of tumours: biological mechanisms and advances in therapy. Nat Rev Cancer. 2014; 14:199-208. [PubMed: 24561446]

2. Nikfarjam M, Muralidharan V, Christophi C. Altered growth patterns of colorectal liver metastases after thermal ablation. Surgery. 2006; 139:73-81. [PubMed: 16364720]

3. Liang B, Zheng CS, Feng GS, et al. Correlation of hypoxia-inducible factor 1alpha with angiogenesis in liver tumors after transcatheter arterial embolization in an animal model. Cardiovasc Intervent Radiol. 2010; 33:806-12. [PubMed: 19937023]

4. Wang B, Xu H, Gao ZQ, Ning HF, Sun YQ, Cao GW. Increased expression of vascular endothelial growth factor in hepatocellular carcinoma after transcatheter arterial chemoembolization. Acta Radiol. 2008; 49:523-9. [PubMed: 18568538]

5. Ayaru L, Pereira SP, Alisa A, et al. Unmasking of alpha-fetoprotein-specific CD4(+) T cell responses in hepatocellular carcinoma patients undergoing embolization. J Immunol. 2007; 178:1914-22. [PubMed: 17237442]

6. Takaki H, Imai N, Contessa TT, et al. Peripheral Blood Regulatory T-Cell and Type 1 Helper T-Cell Population Decrease after Hepatic Artery Embolization. J Vasc Interv Radiol. 2016; 27:1561-8. [PubMed: 27084711]

7. Zhou B, Yan Z, Liu R, et al. Prospective Study of Transcatheter Arterial Chemoembolization (TACE) with Ginsenoside Rg3 versus TACE Alone for the Treatment of Patients with Advanced Hepatocellular Carcinoma. Radiology. 2016; 280:630-9. [PubMed: 26885681]

8. Cosgrove DP, Reyes DK, Pawlik TM, Feng AL, Kamel IR, Geschwind JFH. Open-label single-arm phase II trial of sorafenib therapy with drug-eluting bead transarterial chemoembolization in patients with unresectable hepatocellular carcinoma: Clinical results. Radiology. 2015:277.

9. Yarmohammadi H, Wilkins LR, Erinjeri JP, et al. Efficiency of combined blocking of aerobic and glycolytic metabolism pathways in treatment of N1-S1 hepatocellular carcinoma in a rat model. Journal of Cancer Research and Therapeutics. 2016 In press.

10. Kumar G, Goldberg SN, Wang Y, et al. Hepatic radiofrequency ablation: markedly reduced systemic effects by modulating periablational inflammation via cyclooxygenase- 2 inhibition. Eur Radiol. 2016

11. Brown KT, Do RK, Gonen M, et al. Randomized Trial of Hepatic Artery Embolization for Hepatocellular Carcinoma Using Doxorubicin-Eluting Microspheres Compared With Embolization With Microspheres Alone. J Clin Oncol. 2016; 34:2046-53. [PubMed: 26834067]

12. Sofocleous CT, Petre EN, Gonen M, et al. Factors affecting periprocedural morbidity and mortality and long-term patient survival after arterial embolization of hepatic neuroendocrine metastases. J Vasc Interv Radiol. 2014; 25:22-30. quiz 1. [PubMed: 24365504]

13. Shady W, Petre EN, Gonen M, et al. Percutaneous Radiofrequency Ablation of Colorectal Cancer Liver Metastases: Factors Affecting Outcomes--A 10-year Experience at a Single Center. Radiology. 2016; 278:601-11. [PubMed: 26267832]

14. Sofocleous CT, Violari EG, Sotirchos VS, et al. Radioembolization as a Salvage Therapy for Heavily Pretreated Patients With Colorectal Cancer Liver Metastases: Factors That Affect Outcomes. Clin Colorectal Cancer. 2015; 14:296-305. [PubMed: 26277696]

15. Charlson M, Szatrowski TP, Peterson J, Gold J. Validation of a combined comorbidity index. J Clin Epidemiol. 1994; 47:1245-51. [PubMed: 7722560]

16. Khaidakov M, Szwedo J, Mitra S, et al. Antiangiogenic and antimitotic effects of aspirin in hypoxia-reoxygenation modulation of the LOX-1-NADPH oxidase axis as a potential mechanism. J Cardiovasc Pharmacol. 2010; 56:635-41. [PubMed: 20881612] 
17. Borthwick GM, Johnson AS, Partington M, Burn J, Wilson R, Arthur HM. Therapeutic levels of aspirin and salicylate directly inhibit a model of angiogenesis through a Cox-independent mechanism. FASEB J. 2006; 20:2009-16. [PubMed: 17012253]

18. Spitz GA, Furtado CM, Sola-Penna M, Zancan P. Acetylsalicylic acid and salicylic acid decrease tumor cell viability and glucose metabolism modulating 6-phosphofructo-1-kinase structure and activity. Biochem Pharmacol. 2009; 77:46-53. [PubMed: 18851958]

19. Koga H, Sakisaka S, Ohishi M, et al. Expression of cyclooxygenase-2 in human hepatocellular carcinoma: relevance to tumor dedifferentiation. Hepatology. 1999; 29:688-96. [PubMed: 10051469]

20. Stolina M, Sharma S, Lin Y, et al. Specific inhibition of cyclooxygenase 2 restores antitumor reactivity by altering the balance of IL-10 and IL-12 synthesis. J Immunol. 2000; 164:361-70. [PubMed: 10605031]

21. Hossain MA, Kim DH, Jang JY, et al. Aspirin induces apoptosis in vitro and inhibits tumor growth of human hepatocellular carcinoma cells in a nude mouse xenograft model. Int J Oncol. 2012; 40:1298-304. [PubMed: 22179060]

22. Weinberg, RA. The Biology of Cancer. 2. New York: Garland Science; 2014.

23. Rothwell PM, Fowkes FG, Belch JF, Ogawa H, Warlow CP, Meade TW. Effect of daily aspirin on long-term risk of death due to cancer: analysis of individual patient data from randomised trials. Lancet. 2011; 377:31-41. [PubMed: 21144578]

24. Sahasrabuddhe VV, Gunja MZ, Graubard BI, et al. Nonsteroidal anti-inflammatory drug use, chronic liver disease, and hepatocellular carcinoma. J Natl Cancer Inst. 2012; 104:1808-14. [PubMed: 23197492]

25. Rothwell PM, Wilson M, Price JF, Belch JF, Meade TW, Mehta Z. Effect of daily aspirin on risk of cancer metastasis: a study of incident cancers during randomised controlled trials. Lancet. 2012; 379:1591-601. [PubMed: 22440947]

26. Li JH, Wang Y, Xie XY, et al. Aspirin in combination with TACE in treatment of unresectable HCC: a matched-pairs analysis. Am J Cancer Res. 2016; 6:2109-16. [PubMed: 27725915]

27. Garcia-Tsao G, Bosch J. Management of varices and variceal hemorrhage in cirrhosis. N Engl J Med. 2010; 362:823-32. [PubMed: 20200386]

28. Boas FE, Brody LA, Erinjeri JP, et al. Quantitative Measurements of Enhancement on Preprocedure Triphasic CT Can Predict Response of Colorectal Liver Metastases to Radioembolization. AJR Am J Roentgenol. 2016; 207:671-5. [PubMed: 27248430]

29. Masur K, Niggemann B, Zanker KS, Entschladen F. Norepinephrine-induced migration of SW 480 colon carcinoma cells is inhibited by beta-blockers. Cancer Res. 2001; 61:2866-9. [PubMed: 11306460]

30. Sood AK, Bhatty R, Kamat AA, et al. Stress hormone-mediated invasion of ovarian cancer cells. Clin Cancer Res. 2006; 12:369-75. [PubMed: 16428474]

31. Thiele M, Albillos A, Abazi R, Wiest R, Gluud LL, Krag A. Non-selective beta-blockers may reduce risk of hepatocellular carcinoma: a meta-analysis of randomized trials. Liver Int. 2015; 35:2009-16. [PubMed: 25581713]

32. Lindenauer PK, Pekow P, Wang K, Mamidi DK, Gutierrez B, Benjamin EM. Perioperative betablocker therapy and mortality after major noncardiac surgery. N Engl J Med. 2005; 353:349-61. [PubMed: 16049209] 


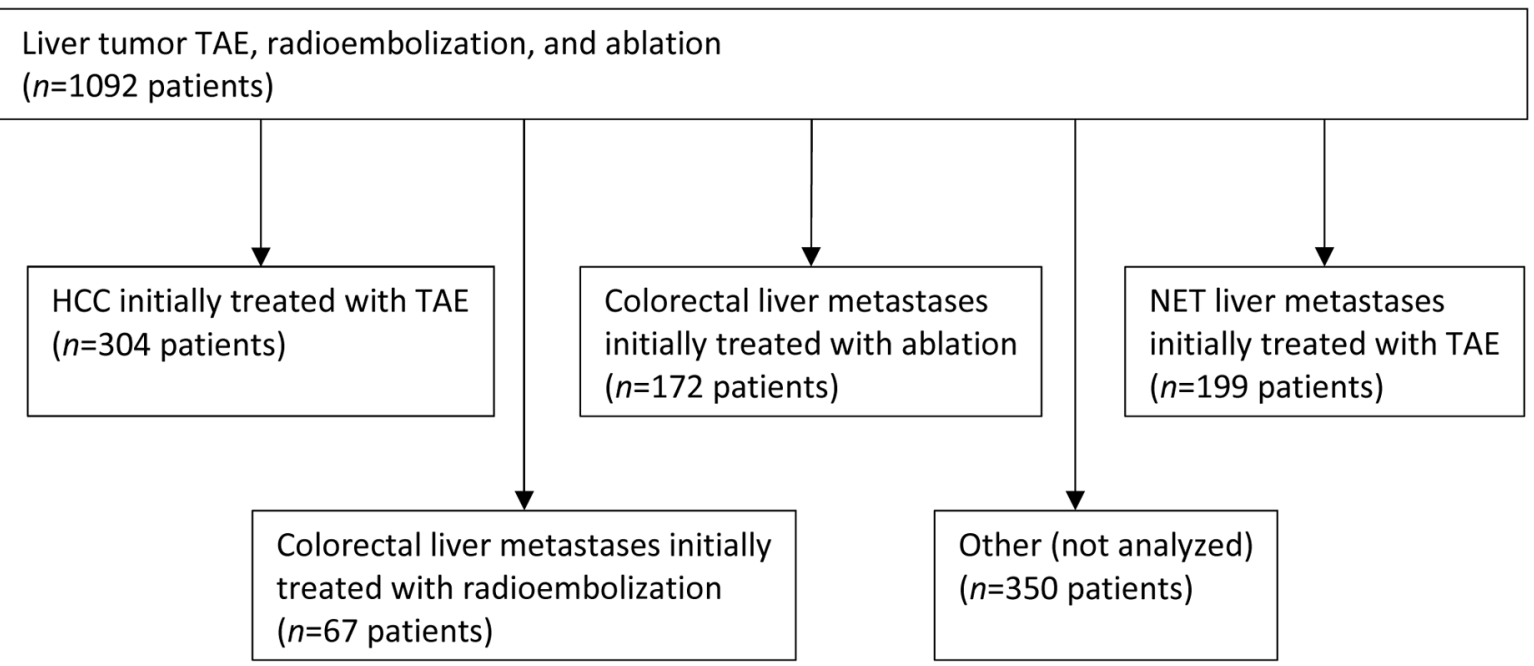

Figure 1.

Treatment groups analyzed. For each of the 4 treatment groups, we calculated Kaplan-Meier survival curves for patients taking versus not taking each of the medications or medication classes in Table 1. The multi-arm study design allows evaluation of whether adjuvant medications have a pathology- or treatment-modality-specific effect. The "other" group is further described in Supplemental Table 1. 


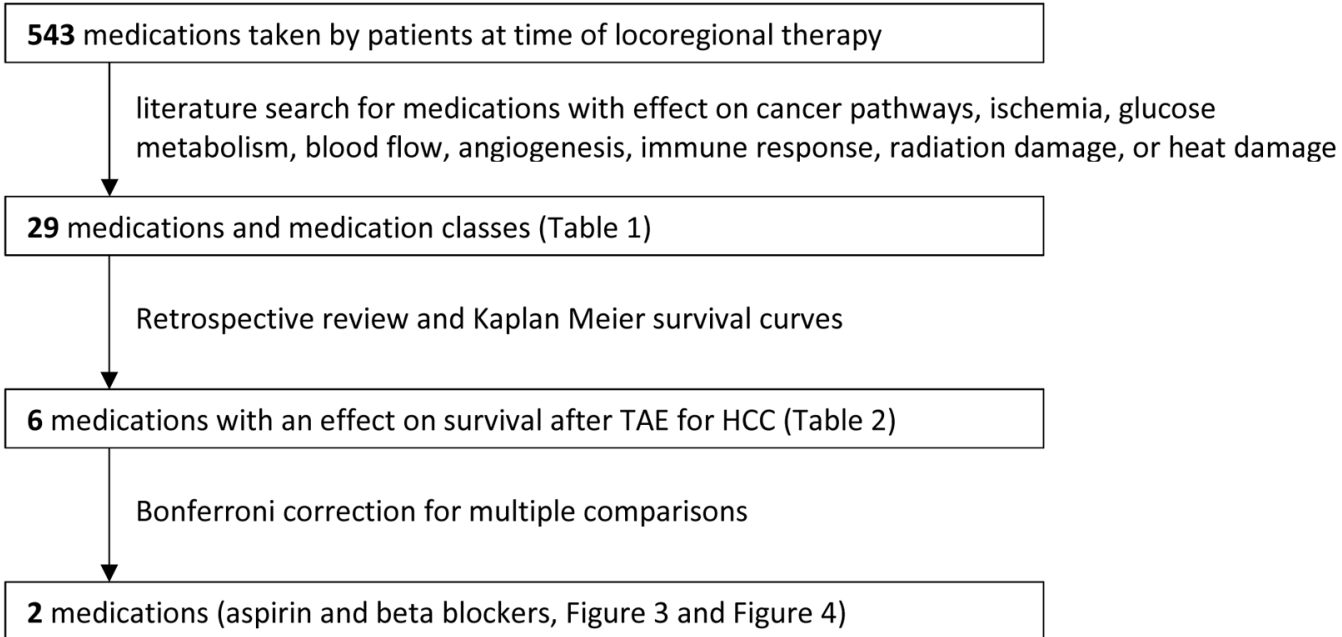

Figure 2.

Identifying adjuvant medications that improve survival when taken at the time of embolization for HCC. 


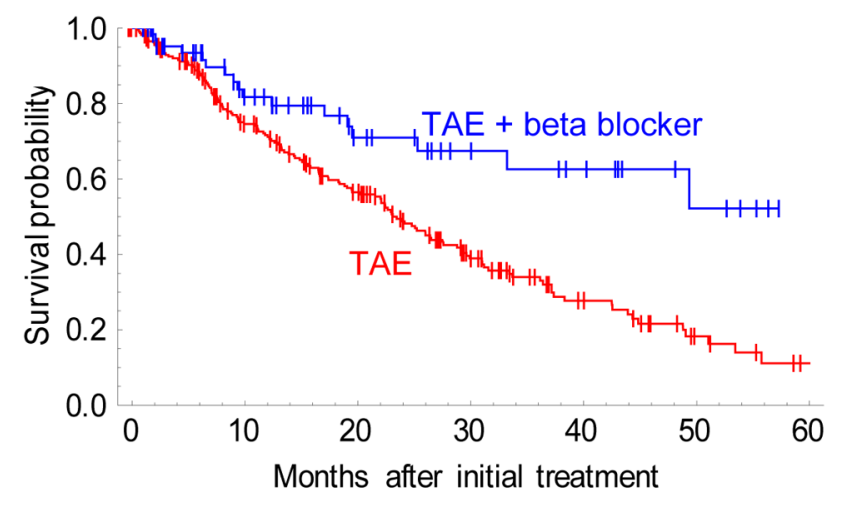

$\begin{array}{lrrrrrrr}\text { Number at risk } & & & & & & & \\ \text { TAE: } & 236 & 152 & 104 & 51 & 25 & 9 & 2 \\ \text { TAE + beta blocker: } & 68 & 39 & 23 & 15 & 11 & 5 & 0\end{array}$

Figure 3.

Survival after transarterial embolization of HCC patients taking beta blockers (blue curve) versus not taking beta blockers (red curve). $p=0.0007$. There was no difference in AJCC stage, Child Pugh score, etiology of underlying liver disease, ECOG performance status, Charlson comorbidity index, prior sorafenib, prior liver resection, or selectivity of the embolization for patients taking versus not taking beta blockers (Supplemental Table 2). 


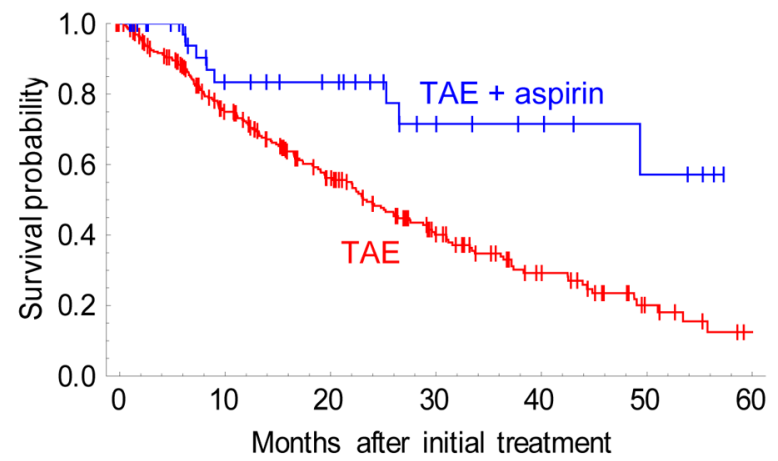

Number at risk

TAE:

$\mathrm{TAE}+$ aspirin:

$\begin{array}{rrrrrrr}262 & 168 & 108 & 56 & 29 & 10 & 2 \\ 42 & 23 & 19 & 10 & 7 & 4 & 0\end{array}$

Figure 4.

Survival after transarterial embolization of HCC patients taking aspirin (blue curve) versus not taking aspirin (red curve). $p=0.0008$. There was no difference in AJCC stage, Child Pugh score, etiology of underlying liver disease, ECOG performance status, Charlson comorbidity index, prior sorafenib, prior liver resection, or selectivity of the embolization for patients taking versus not taking aspirin (Supplemental Table 2). 


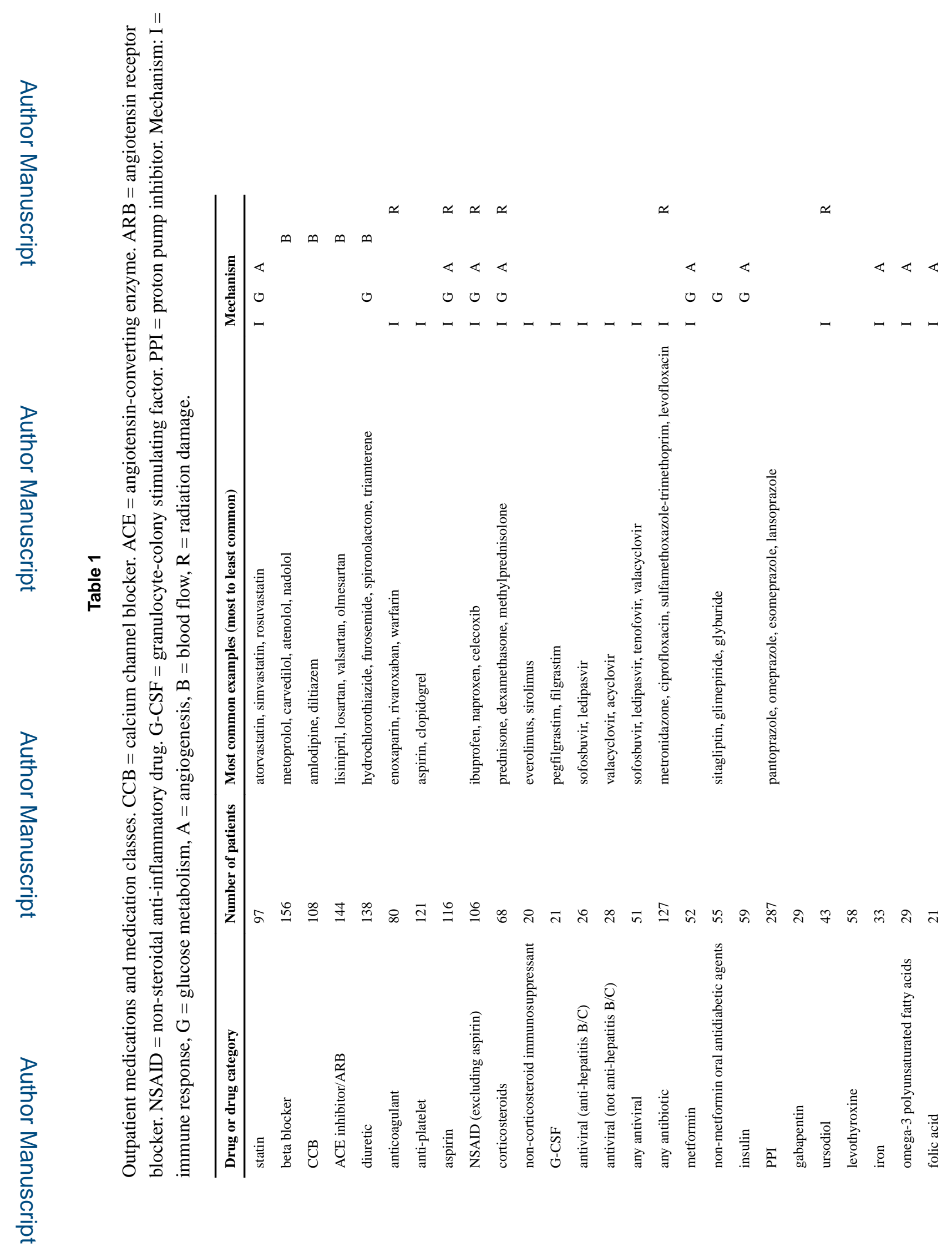

J Vasc Interv Radiol. Author manuscript; available in PMC 2018 July 01. 

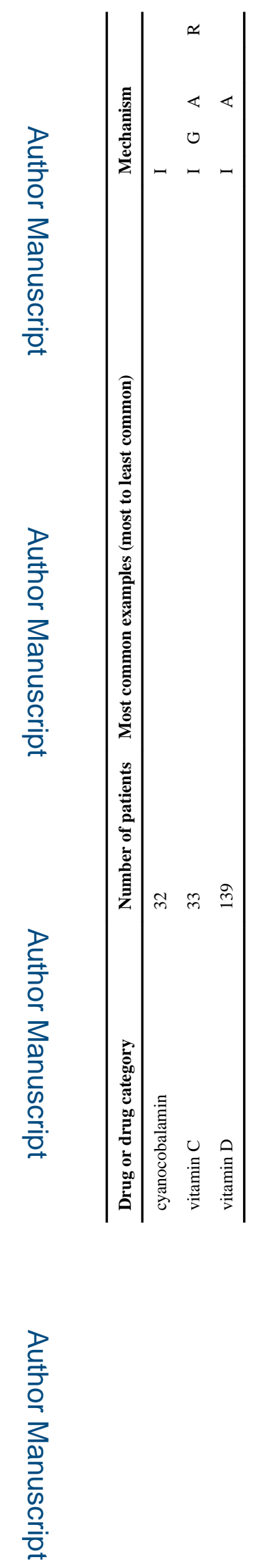


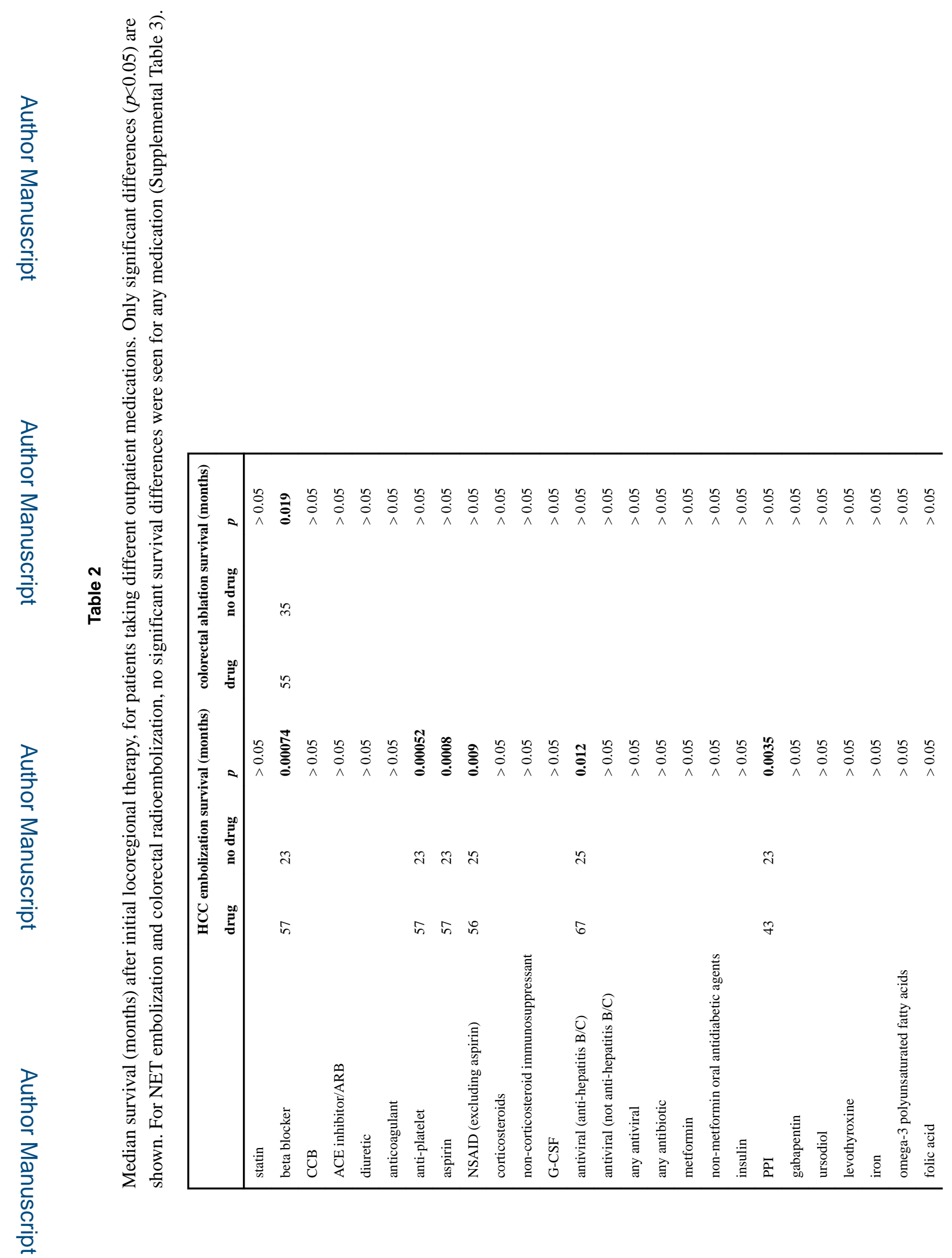

J Vasc Interv Radiol. Author manuscript; available in PMC 2018 July 01. 


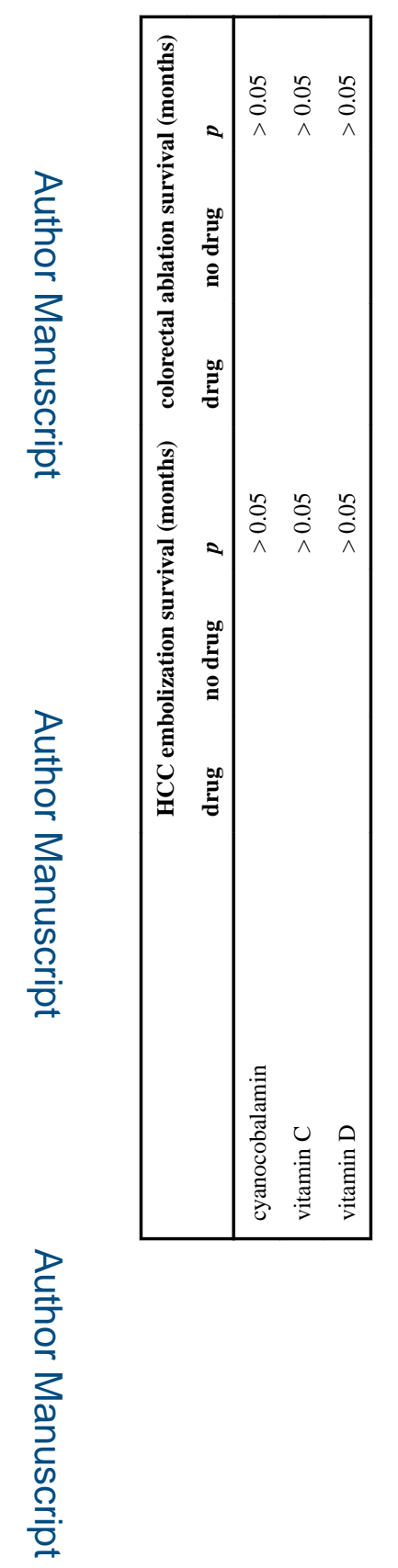

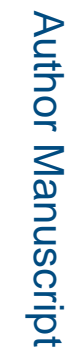

J Vasc Interv Radiol. Author manuscript; available in PMC 2018 July 01. 